\title{
Influence of number of pitches and substrate on the nanostructure and optical properties of ZnS helical sculptured thin films
}

Fatemeh Abdi $^{1}$, Hadi Savaloni ${ }^{1, *}$, Frank Placido ${ }^{2}$

1) Department of Physics, University of Tehran, North-Kargar Street, Tehran, Iran

2) SUPA and Institute of Thin films, Sensors and Imaging, University of The West of Scotland, High Street, Paisley, UK.

3) *) Corresponding Author; Tel: +9821635776, Fax: +982188004781, Email: savaloni@khayam.ut.ac.ir (H. Savaloni)

\section{A b s t r a c t}

$\mathrm{ZnS}$ helical sculptured thin films with different number of pitches were produced on glass (microscope slides) and pre-deposited $7 \mathrm{~nm} \mathrm{ZnS} \mathrm{on} \mathrm{glass} \mathrm{substrate.} \mathrm{Atomic} \mathrm{force} \mathrm{microscopy}$ (AFM) and field emission scanning electron microscopy (FESEM) were used for structural analyses. Crystallographic structure of samples was obtained using x-ray diffraction (XRD) method which confirmed the formation of $\mathrm{ZnS}$ films on the substrates. Optical spectra of the samples were measured using a single beam spectrophotometer for both s- and p-polarized light and at different incident light angles. Optical results showed a strong dependence on the structural void fraction and number of pitches and, due to anisotropy of the helical structure, a dependence on the incident light angle. It is shown that by controlling the growth of these structures the optical spectra can be controlled.

The reversed homogenization theory was used to calculate the complex refractive index of these structures and the percentage of the void fraction in the produced samples. This investigation showed that both real and imaginary parts of the refractive index are dependent on the structural void fraction; structures with larger grains and higher percentage of void fraction having larger real and imaginary parts of the refractive index. Band gap calculations showed that structures with larger grains and higher void fraction have smaller band gaps. A correlation is obtained between 
the band gap energies and the nano-strain developed in the structure of the produced films; band gap energy decreases with nano-strain.

Key words: ZnS; Thin films; Helical sculptured; Optical properties; Reverse homogenization theory; nano-strain

\section{Introduction}

Considering that at nano-scale the properties of nano-particles are strongly dependent on the shape and size of the nano-particle, we may control their properties by controlling their size and shape. Oblique angle deposition (OAD) (vapour incident angle less than $85^{\circ}$ ) and glancing angle deposition (GLAD) (vapor incident angle greater than $85^{\circ}$ ) methods together with the rotation of substrate about its different axes can be used in 3D nano-structure fabrication as sculptured thin films (STF) [1-4]

Sculptured thin films (STFs) are columnar (range between 1 and $100 \mathrm{~nm}$ ) thin films. The columns are the result of clustering at the 1-10 nm level, with atomic self-shadowing controlling their evolution and they can have densities as low as $10 \%-30 \%$ of the bulk material [5]. In order to obtain optical properties of these sculptured thin films, it is assumed that the evaporant in its bulk form is isotropic and any sculptured thin film is a composite material consisting of two phases, namely evaporant and void [4]. The circular Bragg phenomenon occurs in chiral sculptured thin films and is being extensively studied both theoretically [6-14] and experimentally [15-17].

Zinc sulfide $(\mathrm{ZnS})$, because of its wide band gap is a transparent material in the visible and infrared region. Therefore, it is a good candidate for use in optoelectronic devices such as emitter diodes $[18,19]$, information transfer and solar cells [20-22]. It also has vast area of application in display units, sensors [23] and photo catalysts [24-28]. For this reason, $\mathrm{ZnS}$ thin films have been produced 
using different physical and chemical techniques [29-34] and their optical properties such as band gap [35-39], refractive index [40,41] and transmission [42-46] have been extensively investigated. Wang et al. [47] used different deposition angles $\left(0^{\circ}\right.$ to $\left.85^{\circ}\right)$ and produced $\mathrm{ZnS}$ sculptured thin films with tilted columnar structure. The optical properties (refractive index and in-plane birefringence) were obtained. Fabrication of Zigzag $\mathrm{ZnS}$ sculptured thin films is reported by Rahchamani et al. [48].

In this work, oblique angle deposition technique together with rotation of substrate about its surface normal axis is used to produce $\mathrm{ZnS}$ helical structures with different number of pitches on two types of substrates, namely, glass (microscope slide) and glass substrate which was coated with $7 \mathrm{~nm} \mathrm{ZnS}$ film at normal vapor incidence angle and subsequently annealed with flow of argon gas at $340{ }^{\circ} \mathrm{C}$. These samples provided us with not only different types of substrates but also with different surface morphology and initial patterns/nuclei on their surfaces. The structural characteristics of these samples are reported in our earlier work [49] which will be discussed briefly here while their detailed optical properties are investigated and the relationship/correlation between these results is obtained.

\section{Theory (reverse homogenization)}

In order to obtain the refraction index of the structures produced in this work, the reverse homogenization theory was used [50].

In this method the structure of the sculptured thin film is considered as two phases including the material inclusion phase and void fraction phase. Each of these phases is also considered as strings of ellipsoids shapes (Fig. 1). The percentage of the material inclusion and the void fraction are presented as $f_{s}$ and $f_{v},\left(f_{v}=1-f_{s}\right)$ and are given in the Bruggeman's homogenization theory [50]: 
$f_{s} \underline{\underline{A}}_{s}+\left(1-f_{s}\right) \underline{\underline{A}}_{v}=\underline{\underline{0}}$

where $\left(0 \leq f_{s} \leq 1\right)$ is the volume fraction of the ellipsoidal inclusions. The polarizability density dyadic of an ellipsoidal inclusion, $\underline{\underline{A_{s}}}$ embedded in the homogenized composite medium is denoted, on a per unit volume basis, by:

$$
\begin{aligned}
& \underline{\underline{A}}_{s, v}=\varepsilon_{0}\left(\varepsilon_{s, v} \underline{\underline{I}}-\underline{\underline{\varepsilon}}_{r e f}\right) .\left[\underline{\underline{I}}+i \omega \varepsilon_{0} \underline{D}_{s, v} .\left(\varepsilon_{s, y} \underline{\underline{I}}-\varepsilon_{r e f}\right)\right]^{-1} . \\
& \underline{\varepsilon}_{r e f}=\varepsilon_{a} \underline{u}_{z} \underline{u}_{z}+\varepsilon_{b} \underline{u}_{x} \underline{u}_{x}+\varepsilon_{c} \underline{u}_{y} \underline{u}_{y} .
\end{aligned}
$$

is called the local relative permittivity dyadic. The relative permittivity scalars $\varepsilon_{a, b, c}$ are implicit functions of frequency. $u_{x}, u_{y}$ and $u_{z}$ are unit vectors in the Cartesian coordinate system. The permittivity and permeability of free space (vacuum) are, $\varepsilon_{0}=8.854 \cdot 10^{-12} \mathrm{Fm}^{-1}$ and $\mu_{0}=4 \pi \cdot 10^{-7}$ $\mathrm{Hm}^{-1}$, respectively. $\underset{\underline{0}}{0}$ and $\underset{\underline{I}}{\underline{a}}$ are null and unit dyadics, respectively and $\varepsilon_{\mathrm{s}}$ and $\varepsilon_{v}$ are the bulk metal and vacuum permittivities, respectively. The depolarization dyadic of an ellipsoidal region in a homogenized composite medium is given by:

$$
\underline{D}_{s, v}=\frac{2}{i \pi \omega \varepsilon_{0}} \int_{\varphi=0}^{\varphi=\frac{\pi}{2}} \int_{\theta=0}^{\theta=\frac{\pi}{2}} \sin \theta \times \frac{(\sin \theta \cos \varphi)^{2} u_{z} u_{z}+\left(\frac{\cos \theta}{\gamma_{\tau}^{s, v}}\right)^{2} u_{x} u_{x}+\left(\frac{\sin \theta \sin \varphi}{\gamma_{b}^{s, \nu}}\right) u_{y} u_{y}}{(\sin \theta \cos \varphi)^{2} \varepsilon_{a}+\left(\frac{\cos \theta}{\gamma_{\tau}^{s, v}}\right)^{2} \varepsilon_{b}+\left(\frac{\sin \theta \sin \varphi}{\gamma_{b}^{s, v}}\right) \varepsilon_{c}} d \theta d \varphi .
$$

In order to obtain the relative permittivity scalars $\varepsilon_{a, b, c}$, Eq. 1 should be solved numerically. The solution can be readily obtained, using the iterative methods such as Jacobian technique [51]. The factors $\gamma_{b}$ and $\gamma_{\tau}$ relate the lengths of the principal semi-axis of the ellipsoid. 
Once the local relative permittivity dyadic is obtained, the permittivity dyadic of the sculptured structure at each point can be obtained with the use of two rotations dyadics for the ellipsoid about $\mathrm{y}$ and $\mathrm{z}$ axes.

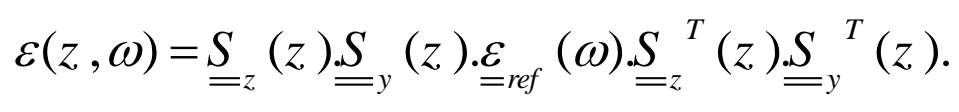

Using the permittivity dyadic in Maxwell equations:

$$
\begin{aligned}
& D(r, \omega)=\varepsilon_{0} \underline{\underline{\varepsilon}}(\omega) \cdot E(r, \omega) . \\
& B(r, \omega)=\mu_{0} . H(r, \omega) .
\end{aligned}
$$

results in Eq. 8 in which field components at two sides of the thin film with thickness of L are related to each other.

$$
\begin{aligned}
& \frac{d}{d z}[f(z, k, \psi, \omega)]=i[p(k, \psi, \omega)][f(z, k, \psi, \omega)], \\
& f(z, k, \psi, \omega)=\left[\begin{array}{l}
e_{x}(z, k, \psi, \omega) \\
e_{y}(z, k, \psi, \omega) \\
h_{x}(z, k, \psi, \omega) \\
h_{y}(z, k, \psi, \omega)
\end{array}\right], \\
& p(k, \psi, \omega)=\omega\left[\begin{array}{cccc}
0 & 0 & 0 & \mu_{0} \\
0 & 0 & -\mu_{0} & 0 \\
0 & -\varepsilon_{0} \varepsilon_{c}(\omega) & 0 & 0 \\
\varepsilon_{0} \varepsilon_{d}(\omega) & 0 & 0 & 0
\end{array}\right]+k \frac{\varepsilon_{d}(\omega)\left[\varepsilon_{a}(\omega)-\varepsilon_{b}(\omega)\right]}{\varepsilon_{a}(\omega) \varepsilon_{b}(\omega)} \sin \psi \cos \psi\left[\begin{array}{cccc}
\cos \psi & 0 & 0 & 0 \\
\sin \psi & 0 & 0 & 0 \\
0 & 0 & 0 & 0 \\
0 & 0 & -\sin \psi & \cos \psi
\end{array}\right] \\
& +\frac{k^{2}}{\omega \varepsilon_{0}} \frac{\varepsilon_{d}(\omega)}{\varepsilon_{a}(\omega) \varepsilon_{b}(\omega)}\left[\begin{array}{ccccc}
0 & 0 & \cos \psi \sin \psi & -\cos ^{2} \psi \\
0 & 0 & \sin ^{2} \psi & -\sin \psi \cos \psi \\
0 & 0 & 0 & 0 \\
0 & 0 & 0 & 0
\end{array}\right]+\frac{k^{2}}{\omega \varepsilon_{0}}\left[\begin{array}{llll}
0 & 0 & 0 & 0 \\
0 & 0 & 0 & 0 \\
-\sin \psi \cos \psi & \cos ^{2} \psi & 0 & 0 \\
-\sin ^{2} \psi & \cos \psi \sin \psi & 0 & 0
\end{array}\right] .
\end{aligned}
$$


In Eq. 8 the quantity $\varepsilon_{d}$ is defined as;

$$
\varepsilon_{d}(\omega)=\frac{\varepsilon_{a}(\omega) \varepsilon_{b}(\omega)}{\varepsilon_{a}(\omega) \cos ^{2} \psi+\varepsilon_{b}(\omega) \sin ^{2} \psi}
$$

We may re-write Eq. 8 in form of;

$[f(L, k, \psi, \omega)]=[M(L, k, \psi, \omega)][f(0, k, \psi, \omega)]$.

where the transformation matrix $\mathrm{M}$ is;

$[M(L, k, \psi, \omega)]=\exp [i p(k, \psi, \omega)]$

If the plane wave vector is incident at an angle $\theta$ to the $\mathrm{z}$ axis of thin film and its projection on the xy plane makes the azimuthal angle $\psi$ with $+x$ axis, then we may write this plane wave in form of;

$$
\begin{array}{ll}
e_{i n c}(z)=\left(a_{s} s+a_{p} p_{+}\right) \exp \left(i k_{0} z \cos \theta\right) & , z \leq 0 \\
h_{i n c}(z)=\sqrt{\frac{\varepsilon_{0}}{\mu_{0}}}\left(a_{s} p_{+}-a_{p} s\right) \exp \left(i k_{0} z \cos \theta\right) . &
\end{array}
$$

$a_{p}$ and $a_{s}$ are perpendicular and parallel components of the incident light amplitude, respectively.

The unit vectors $p$ and $s$ are defined as;

$s=-u_{x} \sin \psi+u_{y} \cos \psi$.

$p_{ \pm}=\mp\left(u_{x} \cos \psi+u_{y} \sin \psi\right) \cos \theta+u_{z} \sin \theta$.

The transmission and reflection components of electric field and magnetic field can be written as;

$$
\begin{array}{ll}
e_{\text {ref }}(z)=\left(r_{s} s+r_{p} p_{-}\right) \exp \left(-i k_{0} z \cos \theta\right) & , z \leq 0 \\
h_{r e f}(z)=\sqrt{\frac{\varepsilon_{0}}{\mu_{0}}}\left(r_{s} p_{-}-r_{p} s\right) \exp \left(-i k_{0} z \cos \theta\right) . & , \quad z \geq 0 \\
e_{\text {tra }}(z)=\left(t_{s} s+t_{p} p_{+}\right) \exp \left(i k\left({ }_{0} z-L\right) \cos \theta\right) & \\
h_{\text {tra }}(z)=\sqrt{\frac{\varepsilon_{0}}{\mu_{0}}}\left(t_{s} p_{+}-t_{p} s\right) \exp \left(i k_{0}(z-L) \cos \theta\right) . &
\end{array}
$$


$t_{p}, t_{s}, r_{p}$ and $r_{s}$ are parallel and perpendicular polarization components of transmission and reflection plane waves. The boundary values of $f$ can be obtained with the use of above equations;

$[f(0, k, \psi, \omega)]=[k(\theta, \psi)]\left[\begin{array}{l}a_{s} \\ a_{p} \\ r_{s} \\ r_{p}\end{array}\right]$.

$[f(L, k, \psi, \omega)]=[k(\theta, \psi)]\left[\begin{array}{l}t_{s} \\ t_{p} \\ 0 \\ 0\end{array}\right]$.

By assuming a $4 \times 4$ matrix for $k$ in form of Eq. 17, we may obtain the transmission and the reflection from Eq. 18 [50];

$$
\begin{aligned}
& k(\theta, \psi)=\left[\begin{array}{lccc}
-\sin \psi & -\cos \psi \cos \theta & -\sin \psi & \cos \psi \cos \theta \\
\cos \psi & -\sin \psi \cos \theta & \cos \psi & \sin \psi \cos \theta \\
-\sqrt{\frac{\varepsilon_{0}}{\mu_{0}}} \cos \psi \cos \theta & \sqrt{\frac{\varepsilon_{0}}{\mu_{0}}} \sin \psi & \sqrt{\frac{\varepsilon_{0}}{\mu_{0}}} \cos \psi \cos \theta & \sqrt{\frac{\varepsilon_{0}}{\mu_{0}}} \sin \psi \\
-\sqrt{\frac{\varepsilon_{0}}{\mu_{0}}} \sin \psi \cos \theta & -\sqrt{\frac{\varepsilon_{0}}{\mu_{0}}} \cos \psi & \sqrt{\frac{\varepsilon_{0}}{\mu_{0}}} \sin \psi \cos \theta & -\sqrt{\frac{\varepsilon_{0}}{\mu_{0}}} \cos \psi
\end{array}\right] . \\
& {\left[\begin{array}{l}
t_{s} \\
t_{p} \\
0 \\
0
\end{array}\right]=[k(\theta, \psi)]^{-1}[M(L, k, \psi, \omega)][k(\theta, \psi)]\left[\begin{array}{l}
a_{s} \\
a_{p} \\
r_{s} \\
r_{p}
\end{array}\right] .}
\end{aligned}
$$

The thin film may be considered as a several thinner layers that are arranged on top of each other in the $z$-direction and to each layer a permittivity constant in matrix form can be attributed. Then 
by solving the Maxwell's equations and implementing the boundary conditions for each layer, a transfer matrix can be obtained. By multiplying these transfer matrices, a total transfer matrix can be achieved.

\section{Experimental details}

As mentioned above the structural analyses of these samples are reported in our earlier work [49]. Their production technique is also given there too. Hence, here we briefly discuss about their fabrication. The chiral nano-sculptured $\mathrm{ZnS}$ thin films with 1, 3 and 5 pitches were deposited on both glass (microscope slide; Thermo Scientific Menzel-Glaser, Soda lime glass) and glass (microscope slide) on which a $7 \mathrm{~nm} \mathrm{ZnS}$ thin film was deposited by electron beam deposition from graphite crucibles at room temperature $\left(25-35^{\circ} \mathrm{C}\right)$ depending on the film thickness (deposition time), and subsequently annealed with flow of argon gas $(250 \mathrm{sccm})$ at $340{ }^{\circ} \mathrm{C}$ temperature. Here onwards we shall call this second substrate as "ZnSgl" substrate. In Fig. 1 of [31] it is shown that islands/grains of $30 \mathrm{~nm}$ in diameter are formed on this substrate which are used as initial nuclei for the growth of $\mathrm{ZnS}$ chiral sculptured thin films. $\mathrm{ZnS}$ with purity $99.99 \%$ in lump form (Goodfellow metals Cambridge Ltd, UK.) was used for the deposition. An Edwards (Edwards E19 A3) coating plant with a base pressure of $2 \times 10^{-7} \mathrm{mbar}$ and coating pressure of 4-8 $\times 10^{-6} \mathrm{mbar}$ depending on the deposition time and the film thickness (number of pitches) during the deposition process was used. The deposition angle was fixed at $80^{\circ}$ (oblique angle) and a substrate azimuthal

rotation speed of 0.04 RPM was chosen. A deposition rate of $1.0 \AA^{-1}$ was used for production of the chiral sculptured thin films. ZnS chiral thin films with one, three and five pitches were produced by rotation of the substrate holder about its surface normal, one, three and five times, respectively. The thickness of each pitch was about $80 \mathrm{~nm}$ (i.e., half structural period, $\Omega=40 \mathrm{~nm}$ ). 
The film thicknesses and column shapes and sizes were measured by field emission electron microscope (FESEM) (Hitachi S-4100 SEM, Japan). The surface physical morphology and roughness was obtained by means of AFM (Auto Probe Pc, Park Scientific Instrument, USA; in non-contact mode, with low stress silicon nitride tip of less than $200 \AA$ radius and tip opening of $18^{\circ}$ ). Crystal structure of these films was obtained using a Siemens D500 x-ray Diffractometer $(\mathrm{CuK} \alpha$ radiation; $40 \mathrm{kV}, 30 \mathrm{~mA})$ with a step size of $0.02^{\circ}$ and count time of $1 \mathrm{sec} / \mathrm{step}$. The reflectance and transmittance spectra of the samples were obtained using a single beam spectrophotometer (Aquila nkd- 8000) in the spectral range of (350-1100 nm) and both s- and ppolarizations in steps of $5 \mathrm{~nm}$ wavelength at different incidence light angles of $10^{\circ}, 30^{\circ}$ and $60^{\circ}$. Considering the helical nano-structures as anisotropic, their optical constants were obtained using the reverse homogenization theory. The percentage of void fraction in the structure of the produced samples was obtained by fitting the theoretical results to the experimental data. The use of extinction coefficient and calculation of absorption coefficient provided us with the data for obtaining the band gap of these structures.

\section{Results and discussion}

\subsection{XRD analyses}

The XRD results of the same samples discussed in [49]. However, in order to observe the degree of crystallinity of the samples by increasing the number of pitches, the XRD patterns of ZnS/glass and $\mathrm{ZnS} / \mathrm{ZnSgl}$ chiral structures with different number of pitches are given in Fig. 2 columns I and II, in a form that are normalized with respect to the (008) diffraction line of the $\mathrm{ZnS} / \mathrm{ZnSgl}$ sample with five pitches (showed highest intensity) while the intensity of this peak is normalized to unity, respectively. Structures with only one pitch due to high porosity and low amount of material 
inclusion do not show any peak. A single peak is obtained for the samples with 3 and 5 pitches which can be assigned to the (008) diffraction line of $\mathrm{ZnS}$ with hexagonal symmetry (with respect to the JCPDS card No: 00-039-1363).

The intensity of this peak is increased immensely with number of pitches in the chiral structure and as pointed out is highest for the $\mathrm{ZnS} / \mathrm{ZnSgl}$ sample with 5 pitches. This shows that the film is grown with a preferred orientation (population of the coherently diffracting domains with (008) orientation is increased), though in case of sculptured thin films in which the axis of crystallography is inclined (changed) the proper identification of preferred orientation should be obtained by performing texture measurements.

It is well known that the optical properties of thin films strongly depend on the film structure, and the nano-strain developed in the film structure. This nano-strain can be calculated from the shift in the position of the peak in the XRD pattern with respect to the standard powder sample [52,53], using:

$$
\varepsilon=\frac{d-d_{0}}{d_{0}},
$$

where $d$ is the plane spacing of the sample and $d_{0}$ is the plane spacing of standard powder sample. Variation of nano-strain for the two sets of samples (i.e., $\mathrm{ZnS} / \mathrm{glass}$ and $\mathrm{ZnS} / \mathrm{ZnSgl}$ ) obtained from the shift of $\mathrm{ZnS}(008)$ diffraction line are shown in columns 2 and 6 of Table 1. Results for all samples show compressive strain which is shifted towards tensile strain (decreased) by increasing the number of pitches while the values of nano-strain obtained for $\mathrm{ZnS} / \mathrm{ZnSgl}$ samples are smaller (shifted more towards tensile strain) than the corresponding $\mathrm{ZnS} /$ glass samples. The compressive nature of the nano-strain obtained for these films may partly be related to the dense bottom layer formed usually in the initial growth stage of sculptured thin films $[54,55]$. The shift towards tensile strain by increasing the number of pitches can be due to increased film thickness (number of 
pitches) which in turn can cause formation of higher fraction of voids in the film structure. This is in line with the results of Messier et al. [56] who proposed a revised structure zone model (SZM), using SEM, TEM and FIM, in which evolutionary growth development of physical structure, column/void sizes are assigned as five sub-zones with sizes: 1-3, 5-20, 20-40, 50-200, and 200$400 \mathrm{~nm}$. This shows that each level of physical structure is about a factor of 3 larger than the previous level. Further Messier [57] in an attempt to quantify morphology of thin films at low adatom mobility, proposed a fractal model that results from natural clustering during random ballistic aggregation of atoms. This is also confirmed by our AFM and FESEM results discussed in the next section.

The difference between the two sets of samples may be related to the $7 \mathrm{~nm} \mathrm{ZnS}$ film deposited on the glass substrate and post-annealed prior to the deposition of chiral structure. This process caused formation of small islands $(30 \mathrm{~nm})$ on the glass substrate on which the chiral structures were grown. Hence, larger structures/grains with wider voids between them are formed on this substrate relative to the films deposited directly on the glass substrates. This leads to shift of compressive nano-strain towards tensile strain (decrease of strain).

\subsection{FESEM and AFM analyses}

In Figs. 3 and 4 (AFM images) and 6 and 7 (FESEM images) of our earlier work [49] on the electrical properties of these films and the discussion therein it was concluded that both the features grown on the $\mathrm{ZnSgl}$ substrates and the voids between them are larger than those produced on the glass substrates. This was related to the initial nucleation (template) of the $\mathrm{ZnSgl}$ substrate. In addition, it was observed that both grain size and void fraction increase with film thickness (number of pitches). In order to visualize the nature of the produced samples the FESEM cross- 
section images of both sets of the samples are given in Fig. 3. In addition, the results of grain sizes and the film surface roughness obtained from the AFM analyses are also given in Table 1. Theoretical predictions and experimental results [58-62], show that larger features grow on top of peaks and thin needle-like features form on the smooth areas of the surface, while one should also consider the shadowing and self-shadowing effects in the OAD and GLAD depositions. This will cause higher porosity as can be seen in case of helical $\mathrm{ZnS}$ films grown on $\mathrm{ZnSgl}$ relative to the glass substrate.

Savaloni and Esfandiar [63] have also discussed the role of the dense bottom layer, which forms in addition to the nano-sculptured thin films, on the growth of sculptured thin films. They mention that the bottom layer surface due to the shadowing effect in oblique incidence tends to be rough, hence providing peaks that can shadow the lower areas. The subsequent film will grow predominantly on these peaks with the lower areas not receiving any (or less) flow of evaporant. This bottom layer was also observed for our $\mathrm{ZnS}$ films [49].

\subsection{Optical results}

The optical spectra (i.e., reflectance, transmission and absorption) of the $\mathrm{ZnS}$ helical sculptured thin films with different number of pitches obtained at different incident light angles (i.e., $10^{\circ}, 30^{\circ}$ and $60^{\circ}$ ) for both s- and p-polarizations are given in Figs. 4(I-III). Fig. 4(I) shows these spectra for the $\mathrm{ZnS} /$ glass film with one pitch. It can be observed that at $10^{\circ}$ incident light angle both s- and ppolarization spectra are similar and have a transmission value of about $90 \%$ in the wavelength region of visible and infra-red light $(\lambda>400 \mathrm{~nm})$ while they show negligible reflection and absorption in this region. In the lower wavelength region $(\lambda<400 \mathrm{~nm})$ a sudden drop in the transmission is obtained which can be the result of wide band gap in the structure of $\mathrm{ZnS}$ and high absorption in this region. It can also be seen that variation of the incident light angle has no effect 
on the absorption spectra while both transmission and reflection spectra are strongly dependent on the incident light angle. The other feature which can be distinguished is the increase of transmission and decrease of reflection with increase of incident light angle for p-polarized light while this is opposite in case of s-polarized light. In fact this behavior can be clearly observed for all structures (i.e., one, three and five pitches) in Figs. 4(II) and 4(III). In Fig. 4(I(c)) in case of ppolarized light incident at $60^{\circ}$ the reflection is reduced almost to zero percent (see the inset in this figure) and transmission is increased almost to $100 \%$. This is the result of closeness of the incident light angle to the Brewster angle.

Optical spectra of the ZnS/glass films with three and five pitches are given in Figs. 4(II) and 4(III), respectively. Absorption peaks can be seen in both figures the intensity and number of which increase with film thickness (number of pitches). In the case of the structure with three pitches one absorption peak can be distinguished at about $460 \mathrm{~nm}$ while for the structure with five pitches three absorption peaks appear at wavelengths of $390 \mathrm{~nm}, 460 \mathrm{~nm}$ and $650 \mathrm{~nm}$. In addition, one can also point out that for p-polarized incident light increasing the incident light angle leads to an increase in transmission and a widening of the absorption peak, while the value of reflection is reduced to near zero percent. The behavior for s-polarized light is opposite to the p-polarized light.

The optical spectra of $\mathrm{ZnS} / \mathrm{ZnSgl} \mathrm{samples} \mathrm{with} \mathrm{one,} \mathrm{three} \mathrm{and} \mathrm{five} \mathrm{pitches} \mathrm{are} \mathrm{given} \mathrm{in} \mathrm{Fig.} \mathrm{5(I-}$ III). Comparison of these figures with the corresponding results for the samples deposited on glass substrates show that these samples have higher reflection and lower transmission than those produced on glass substrates (Fig. 4). This should be due to the $7 \mathrm{~nm} \mathrm{ZnS} \mathrm{film} \mathrm{at} \mathrm{the} \mathrm{base} \mathrm{of} \mathrm{these}$ films that may reduce the transmission.

Similar conclusions as those mentioned above for $\mathrm{ZnS}$ films deposited on glass substrates can be deduced for these films too. However, in addition one should mention that the absorption peaks 
appearing in the spectra of the samples on $\mathrm{ZnSgl}$ substrates show a shift towards longer wavelengths. This can be due to the formation of larger grains (features) in the structure of these films relative to those produced on glass substrates, which in turn results in smaller band gaps. Arenas et al. [64] in their study of $\mathrm{ZnS}$ thin films of different thickness produced by chemical bath deposition and post annealed in air obtained similar peaks in their optical spectra, but they did not mention the cause/source of these peaks. They considered that reflectance is mainly due to the air ZnS film interface and calculated the absorption and the band gap of their films. However, we are of the opinion that because these calculated absorption maxima match the minima in the reflectance spectrum are due to optical interference between top and bottom surfaces of the film. Figure 6 compares the position of the maxima for the two types of samples. The absorption peak for the structure with three pitches formed on $\mathrm{ZnSgl}$ substrate (Fig. 5(II) at $600 \mathrm{~nm}$ appears at longer wavelengths relative to the similar structures on glass substrate. This indicates that structures formed on $\mathrm{ZnSgl} \mathrm{substrates} \mathrm{have} \mathrm{smaller} \mathrm{band} \mathrm{gaps} \mathrm{relative} \mathrm{to} \mathrm{those} \mathrm{formed} \mathrm{on} \mathrm{glass}$ substrates. Nadeem and Ahmad [43] have also reported this kind of shift and related it to smaller band gap as a result of increased thickness for $\mathrm{ZnS}$ thin films.

The theoretical approach of reverse homogenization [50] (described in Section 2) was used to obtain the refraction index of the structures produced in this work. This was done by fitting the theoretical results to the experimental transmission and reflection data. These are compared in Figs. 7 and 8 where the percentages of void fraction for $\mathrm{ZnS} /$ glass and $\mathrm{ZnS} / \mathrm{ZnSgl}$ helical sculptured thin films with one, three and five pitches were obtained as $(0.02,0.30$ and 0.45$)$ and $(0.05,0.35$ and 0.5$)$, respectively.

Figs. 9(a and b) and Figs. 9(c and d) show the real and imaginary parts of the refraction index for $\mathrm{ZnS} /$ glass and $\mathrm{ZnS} / \mathrm{ZnSgl} \mathrm{helical} \mathrm{structures} \mathrm{with} \mathrm{different} \mathrm{number} \mathrm{of} \mathrm{pitches,} \mathrm{respectively.} \mathrm{In} \mathrm{Fig.}$ 
9(a) it is obvious that the real part of the refraction index for the structure with one pitch is lowest and almost constant. This leads to the low reflection of this structure. The value of absorption for this structure is nearly zero which in turn as shown in Fig. 9(b) results in zero value for the imaginary part of the refraction index. The increase (maximum) at low wavelengths of the imaginary part of the refraction index could be due to the position of the band gap of this structure in this energy range. Both real and imaginary parts of refractive index increase with number of pitches (Figs. 9(b) and 9(d)). This causes the decrease of transmission and in turn the increase in reflection and absorption. In addition, it can be seen that the number of minima increases in the plots of real part of refraction index with the number of pitches (Figs. 9(a) and 9(c)). These minima are due to high absorption with increase of film thickness. Positions of these minima are almost consistent with the peaks observed (absorption peaks) in the optical spectra of these samples (Figs. 4 and 5). Comparison of the results for $\mathrm{ZnS} /$ glass with $\mathrm{ZnS} / \mathrm{ZnSgl}$ in Fig. 9 reveals larger values for the latter samples. This is due to increased grain sizes in the $\mathrm{ZnS} / \mathrm{ZnSgl}$ samples as a result of growth of $\mathrm{ZnS}$ helical thin film on pre-deposited $7 \mathrm{~nm} \mathrm{ZnS}$ film (template).

\subsection{Band gap of the ZnS helical sculptured structures}

The band gap of the $\mathrm{ZnS}$ helical sculptured thin films with different number of pitches on the two different types of substrates (i.e., glass and $\mathrm{ZnSgl}$ ) were calculated by obtaining the absorption coefficient in the following way;

$\alpha=\frac{4 \pi \mathrm{k}}{\lambda}$

where $k$ is the imaginary part of the refractive index and $\lambda$ is the wavelength of the light. Equation 10 gives the relationship between absorption coefficient and the band gap; 


$$
\alpha=\frac{A}{h v}\left(h v-E_{g}\right)^{n},
$$

where $A$ is a constant, $E_{g}$ is the energy of the incident photon and the value of $n$ is defined by the transition type. For direct transitions, $n=1 / 2$ and for allowed indirect transitions, forbidden direct transitions and forbidden indirect transitions $n=3 / 2,2$ and 3, respectively. In the case of $\mathrm{ZnS}$ with allowed direct transitions, $n=1 / 2$ is considered and the extrapolation of the linear part of the plot of $(\alpha h v)^{2}$ versus $(h v)$ should give the value of the band gap.

The plots of $(\alpha h v)^{2}$ versus $(h v)$ for $\mathrm{ZnS} /$ glass and $\mathrm{Zns} / \mathrm{ZnSgl}$ helical sculptured thin films with one, three and five pitches are given in Fig. 10(a) and Fig. 10(b), respectively. The values of band gap energy obtained in Fig. 10(a) are $3.5 \mathrm{eV}, 3.4 \mathrm{eV}$ and $3.3 \mathrm{eV}$ for films with one, three and five pitches, respectively. Similar procedure for $\mathrm{ZnS} / \mathrm{ZnSgl}$ films showed values of $3.4 \mathrm{eV}, 3.3 \mathrm{eV}$ and $3.18 \mathrm{eV}$.

Comparison of the results for different number of pitches in each set (films produced on different substrates) shows that the band gap energy decreases with increasing the number of pitches and the band gap energies obtained for the structures produced on $\mathrm{ZnSgl}$ substrate are smaller than those for the similar structures produced on glass substrate. These observations can be the results of variations of the grain size (feature size) and the nano-strain developed in the structure of the samples as explained below. Our FESEM and the AFM results (reported in [49] and given in Table 1) show that grain size increases with film thickness which is in agreement with the results of Messier et al. [56]. Hence, as it is well known the larger grains should show smaller band gap energies. As mentioned in [49] due to pre nucleation process (formation of template) of the $\mathrm{ZnSgl}$ substrate larger grains (features) were grown on this substrate than those on glass substrate. Therefore, smaller band gap energies should be obtained for these samples (Table 1). 
On the other hand, one may relate these results to the nano-strain which is developed in the structure of the produced films. Ortuno-Lopez et al. [65] studied the optical band gap of CdS films and found that energy band gap of their films decreased with the amount of strain. Our calculation of the nano-strain given in Table 1 shows that for both sets of samples the nano-strain decreases with increasing the number of pitches and this has led to decrease of band gap energy which is consistent with Ortuno-Lopez et al.'s finding. Comparison of the nano-strain values obtained for $\mathrm{ZnS} / \mathrm{ZnSgl}$ samples with those of $\mathrm{ZnS} /$ glass samples shows that corresponding values of the former are smaller than those of the latter samples and this has resulted in smaller band gap energy for the $\mathrm{ZnS} / \mathrm{ZnSgl}$ samples.

\section{Conclusions}

$\mathrm{ZnS}$ helical sculptured thin films with different number of pitches were produced on glass and $\mathrm{ZnSgl}$ (glass substrates with $7 \mathrm{~nm} \mathrm{ZnS} \mathrm{film} \mathrm{annealed} \mathrm{to} \mathrm{produce} \mathrm{pre-nucleated/patterned} \mathrm{substrate)}$ substrates. Structural differences were obtained using microscopic analyses, while optical properties of these films were obtained using spectrophotometery with both s- and p-polarized lights at different incident light angles. Optical results showed higher absorption with increasing the number of pitches in both group of films and higher reflection for films deposited on $\mathrm{ZnSgl}$ substrates relative to those produced on glass substrates. The refractive index of the films was calculated by introducing the helical geometry of the films in the reverse homogenization theory. Results showed that both real and imaginary parts of the refractive index increase with number of pitches. Microscopic analyses showed larger grains (features) for films deposited on $\mathrm{ZnSgl}$ substrates relative to those deposited on glass substrates which in turn resulted in higher refraction index for these films. 
In addition, band gap energy calculation of both group of films (depending on type of substrate used) showed that in each group of films the band gap energy decreases with increasing the number of pitches. This is due to increase of grain (feature) size. For the same reason films produced on $\mathrm{ZnSgl} \mathrm{substrates} \mathrm{showed} \mathrm{smaller} \mathrm{band} \mathrm{gap} \mathrm{energy} \mathrm{relative} \mathrm{to} \mathrm{those} \mathrm{deposited} \mathrm{on} \mathrm{glass} \mathrm{substrates.}$ In addition the crystal structure analyses of the samples showed a direct relationship between the band gap energy variation and the nano-strain developed in the structure of the films.

\section{Acknowledgments}

This work was carried out with the support of the University of Tehran and the Iran National Science Foundation (INSF). H.S. is grateful to the centre of excellence for structural and microscopic properties of matter, Department of Physics, University of Tehran for partial support of this work.

\section{References:}

[1] S. R. Kennedy, M. J. Brett, Nano Lett., 2, 1, (2002).

[2] ; K. Robbie, M.J. Brett, A. Lakhtakia, J. Vac. Sci. Technol. A13 (1995) 2991.

[3] K. Robbie, G. Beydaghyan, T. Brown, C. Dean, J. Adams, C. Buzea, Rev. Sci. Instrum. 75 (2004) 1089.

[4] K. Robbie, PhD Thesis, University of Alberta, 1998.].

[5] Messier R, Venugopal VC, Sunal PD. J Vac Sci Technol A 2000;18:1538.

[6] V.C. Venugopal, A. Lakhtakia, Proc. R. Soc. London A 456 (2000) 125. 
[7] J. Wang, A. Lakhtakia, J.B. Geddes III, Optik 113 (2002) 213.

[8] V.C. Venugopal, A. Lakhtakia, in: O.N. Singh, A. Lakhtakia (Eds.), Electromagnetic

Fields in Unconventional Materials and Structures, Wiley, New York, 2000, p. 151.

[9] V.C. Venugopal, A. Lakhtakia, Eur. J. Phys. Appl. Phys. 10 (2000) 173.

[10] M.D. Pickett, A. Lakhtakia, J.A. Polo, Optik 115 (2004) 393.

[11] M.W. McCall, A. Lakhtakia, J. Mod. Opt. 47 (2000) 973 corrections: 50 (2003) 2807.

[12] M.W. McCall, Math. Comput. Modell. 34 (2001) 1483.

[13] F. Babaei, H. Savaloni, Opt. Commun. 278 (2007) 221.

[14] F. Babaei, H. Savaloni, Opt. Commun. 278 (2007) 321.

[15] A. Lakhtakia, M.W. McCall, J.A. Sherwin, Q.H. Wu, I.J. Hodgkinson, Opt. Commun. $194(2001) 33$.

[16] I. Hodgkinson, Q.H. Wu, B. Knight, A. Lakhtakia, K. Robbie, Appl. Opt. 39 (2000) 642.

[17] Q. Wu, I.J. Hodgkinson, A. Lakhtakia, Opt. Eng. 39 (2000) 1863.

[18] W. H.Yang, G. C. Schatz, R. P. V. Duyne, J. Chem. Phys., 103, 15, (1995).

[19] H. Katayama, S. Oda, H. Kukimoto, Appl. Phys. Lett., 27, 657, (1975).

[20] N. Fathy, R. Kobayashi, M. Ichimura, Mater. Sci. Eng., B 107, 271, (2004).

[21] I. C. Nducwe, Sol. Energy Mater. Sol. Cells, 40, 123, (1996).

[22] R. O. Borges, D. Lincot, J. Videl, photovoltaic solar energy conference, (PVSEC-6) 862, (1992).

[23] T. V. Prevenslik, J. Lumen., 1210, 87, (2000).

[24] D. Chen, F. Huang, G. Ren, D. Li, M. Zheng, Y. Wang, Z. Lin, Nano scale., 2, 2062, (2010). 
[25] S. Yanagida, K. Mizumoto, C. J. Pac, J. Am. Chem. Soc., 108, 647, (1986).

[26] J. S. Hu, L. L. Ren, Y. G. Guo, H. P. Liang, M. A. Cao, L. J. Wan, C. L. Bai, Angew. Chem., 44, 1269, (2005).

[27] S. Kohtani, Y. Ohama, Y. Ohno, I. Tsuji, A. Kudo, R. Nakagaki, Chem. Lett., 34, 1056, (2005).

[28] H. Fujiwara, H. Hosokawa, K. Murakoshi, Y. Wada, S. Yanagida, Langmuir, 14, 5154, (1998).

[29] M. P .Valkonen, S .Lindroos, T. Kanniainen, M .Leskela, U. Tapper, E. Kauppinen, Appl. Sur. Sci., 120, 58, (1997)

[30] J. M. Dona, J. Herrero, J .Electrochem. Soc., 141, 205, (1994).

[31] K. Ichino, T. Onishi, Y. Kawakami, S. Fujita, J. Crystal Growth, 138, 28, (1994).

[32] Z. J. Xin, R.J. Peaty, H. N. Rutt, R. W. Eason, Semicond. Sci. Technol., 14, 695, (1999).

[33] K. A. Dhese, J. E. Nicholls, W. E. Hagston, P. J .Wrigth, B. Cockayne, J. J. Davies, J. Crystal Growth, 138, 140, (1994).

[34] J .Ihanus, M. Ritala, M. Leskelaand, T. Prohaska, R. Resch, G. Friedbacher, Appl. Surf. Sci., 120, 43, (1997)

[35] J. Lee, S. Lee, S. Cho, S. Kim, I. Y. Park, Y. D. Choi, Materials Chemistry and Physics, 77, 254, (2002).

[36] C. T. Tsai, D. S. Chuu, G. L. Chen, S. L. Yang, J. Appl. Phys., 79, 9105, (1996).

[37] P. K. Ghosh, S. Jana, S. Nandy, K. K. Chattopadhyay, Materials Research Bulletin, 42, 505, (2007).

[38] R. K. Nkum, A. A. Adimado, H. Totoe, Mater. Sci. Eng., B, 55, 102, (1998).

[39] H. J. Lee, S. Lee, Current Applied Physics, 7, 193, (2007).

[40] J. P. Borah, J. Barman, K. C. Sarma, Chalcogenide Letters., 59, 201, (2008). 
[41] R. Zhang, B. Wang, H. Zhang, L. Wei, Appl. Surf. Sci., 241, 435, (2005).

[42] A. Ates, M. Yildirim, M. Kundakci, A. Astam, Materials Science in Semiconductor Processing, 10, 281, (2007).

[43] M.Y. Nadeem, W. Ahmed, Turk. J. Phy., 24, 651, (2000).

[44] X. Wu, F. Lai, L. Lin, J. Lv, B. Zhuang, Q. Yan, Z. Huang, Appl. Surf. Sci., 254, 6455, (2008).

[45] A. U. Ubale, D. K. Kulkarni, Bull. Mater. Sci., 28, 43, (2005).

[46] Y. P. V. Subbaiah, P. Prathap, K. T. R. Reddy, Appl. Surf. Sci., 253, 2409, (2006).

[47] S. Wang, X. Fu, G. Xia, J. Wang, J. Shao, Z. Fan, Applied Surface Science 252 (2006) 87348737.

[48] S. Z. Rahchamani, H. R. Gholipour Dizaji, M. H. Ehsani, Procedia Materials Science 11 (2015) 464-468.

[49] F. Abdi, H. Savaloni, Appl. Surf. Sci., 330, 74, (2015).

[50] A. Lakhtakia, R. Messier, Sculptured Thin Films, Nanoengineered Morphology and Optics, Bellingham, WA:SPIE, (2005).

[51] J. A. Sherwin, A. Lakhtakia, Opt. Commun., 214, 231, (2002).

[52] H. Savaloni, M. Gholipour-Shahraki, M. A. Player, J. Phys. D: Appl. Phys. 39 (2006) 2231.;;

[53] F.H. Chung, D.K. Smith, Industrial applications of X-ray diffraction, Marcel Dekker Publisher, 1999.

[54] H. Alouach, G.J. Mankey, J. Vac. Sci. Technol. A22 (2004) 1379.

[55] H. Savaloni, F. Babaei, S. Song, F. Placido, Applied Surface Science 255 (2009) 8041-8047.

[56] R. Messier, A.P. Giri, R.A. Roy, J. Vac. Sci. Technol. A 2 (1984) 500.

[57] R. Messier, J. Vac. Sci. Technol. A 4 (1986) 490. 
[58] D. J. Srolovitz, J. Vac. Sci. Technol., A 4, 2925, (1986).

[59] H. Savaloni, M. G. Shahraki, Nanotechnology, 15, 311, (2004).

[60] P. Bai, J. F. M. Donald, T. M. Lu, M. J. Costa, J. Vac. Sci. Technol., A 9, 2113, (1991).

[61] H. Savaloni, E. Gu, M. A. Player, G.V. Marr, Vacuum, 43, 965, (1992).

[62] H. Savaloni, S. B. Najmi, Vacuum, 66, 49, (2002).

[63] A. Esfandiar, H. Savaloni, F. Placido. Physica E: Low-dimensional Systems and Nanostructures, 50, 88, (2013).

[64] O. L. Arenas, M. T. S. Nair and P. K. Nair, Semicond. Sci. Technol. 12 (1997) 1323-1330]

[65] M. B. Ortuno-Lopez, M. Sotelo-Lerma, A. Mendoza-Galvan, R. Ramirez-Bon, Vacuum 76 (2004) 181-184]

\section{Figure captions:}

Figure 1. A sculptured thin film column which is considered as a string of identical long ellipsoids with shape factors of $\gamma_{\tau}$ and $\gamma_{b}$.

Figure 2. X-ray diffraction patterns of $\mathrm{ZnS} /$ glass (column I) and $\mathrm{ZnS} / \mathrm{ZnSgl}$ (column II) chiral sculptured thin films with different number of pitches. a) 1 pitch, b) 2 pitches, c) 3 pitches. Figure 3. FESEM cross-section images of ZnS/glass (column I) and $\mathrm{ZnS} / \mathrm{ZnSgl}$ (column II) chiral sculptured thin films with different number of pitches. a) 1 pitch, b) 2 pitches, c) 3 pitches. 
Figure 4. Optical spectra of helical ZnS/glass sculptured thin films with different number of pitches: I) one pitch; II) three pitches; III) five pitches, obtained using different incident light angles a) $10^{\circ}$, b) $30^{\circ}$, c) $60^{\circ}$.

Figure 5. Optical spectra of helical $\mathrm{ZnS} / \mathrm{ZnSgl}$ sculptured thin films with different number of pitches: I) one pitch; II) three pitches; III) five pitches, obtained using different incident light angles a) $10^{\circ}$, b) $30^{\circ}$, c) $60^{\circ}$.

Figure 6. Shift of maximum of absorption towards shorter wavelengths for helical $\mathrm{ZnS} / \mathrm{ZnSgl}$ sculptured thin films relative to helical $\mathrm{ZnS} /$ glass sculptured thin films.

Figure 7. Optical spectra of helical ZnS/glass sculptured thin films with different number of pitches: a) one pitch; b) three pitches; c) five pitches, obtained using $10^{\circ}$ incident light angle.

Solid line) results of reverse homogenization theory; Dashed line) experimental results.

Figure 8. Optical spectra of helical $\mathrm{ZnS} / \mathrm{ZnSgl}$ sculptured thin films with different number of pitches: a) one pitch; b) three pitches; c) five pitches, obtained using $10^{\circ}$ incident light angle. Solid line)results of reverse homogenization theory; Dashed line) experimental results.

Figure 9. Real and imaginary parts of fractive index of helical $\mathrm{ZnS}$ sculptured thin films with different number of pitches (N) on glass substrates (a and b) and on $\mathrm{ZnSgl} \mathrm{substrates} \mathrm{(c} \mathrm{and} \mathrm{d).}$

Figure 10. Band gap of helical $\mathrm{ZnS}$ sculptured thin films with different number of pitches (N) on glass substrates (a) and on $\mathrm{ZnSgl}$ substrates (b). 
Table 1. Data obtained from AFM and XRD analyses

\begin{tabular}{|c|c|c|c|c|c|c|c|c|}
\hline \multirow{2}{*}{$\begin{array}{l}\text { Number } \\
\text { of } \\
\text { pitches }\end{array}$} & \multicolumn{4}{|c|}{ ZnS/Glass } & \multicolumn{4}{|c|}{$\mathrm{ZnS} / \mathrm{ZnSgl}$} \\
\hline & $\varepsilon \times 10^{-4}$ & $\begin{array}{l}\mathrm{D}_{\mathrm{AFM}} \\
(\mathrm{nm})\end{array}$ & $\begin{array}{l}R_{\text {ave }} \\
(\mathrm{nm})\end{array}$ & $\begin{array}{l}\mathrm{R}_{\mathrm{rms}} \\
(\mathrm{nm})\end{array}$ & $\varepsilon \times 10^{-4}$ & $\begin{array}{l}\mathrm{D}_{\text {AFM }} \\
(\mathrm{nm})\end{array}$ & $\begin{array}{l}\text { Rave } \\
(\mathrm{nm})\end{array}$ & $\begin{array}{l}\mathrm{R}_{\mathrm{rms}} \\
(\mathrm{nm})\end{array}$ \\
\hline 1 & - & 64 & 1.8 & 2.24 & - & 78 & 2.1 & 2.67 \\
\hline 3 & -73 & 90 & 3.57 & 4.52 & -66 & 98 & 4.96 & 6.19 \\
\hline 5 & -59 & 104 & 4.44 & 5.7 & -49 & 124 & 4.91 & 6.16 \\
\hline
\end{tabular}




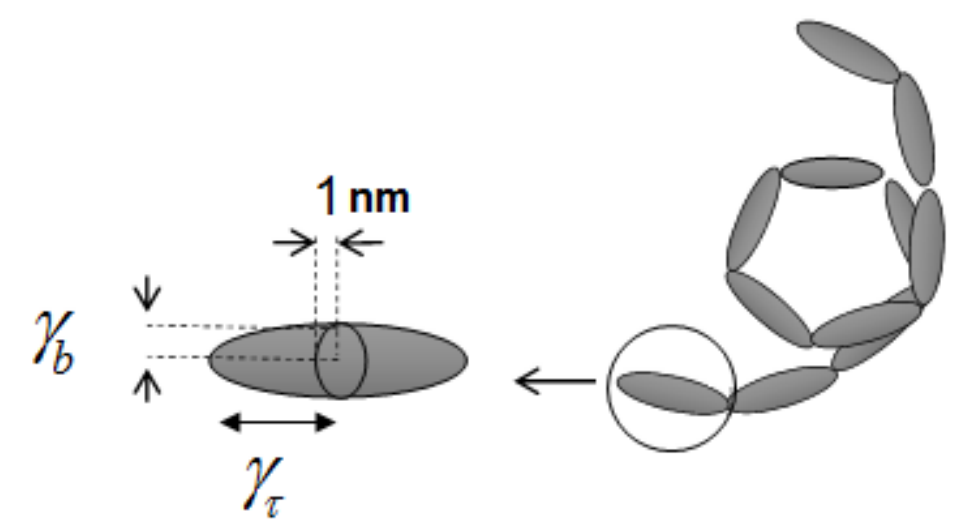

Figure 1. A sculptured thin film column which is considered as a string of identical long ellipsoids with shape factors of $\gamma_{\tau}$ and $\gamma_{b}$. 

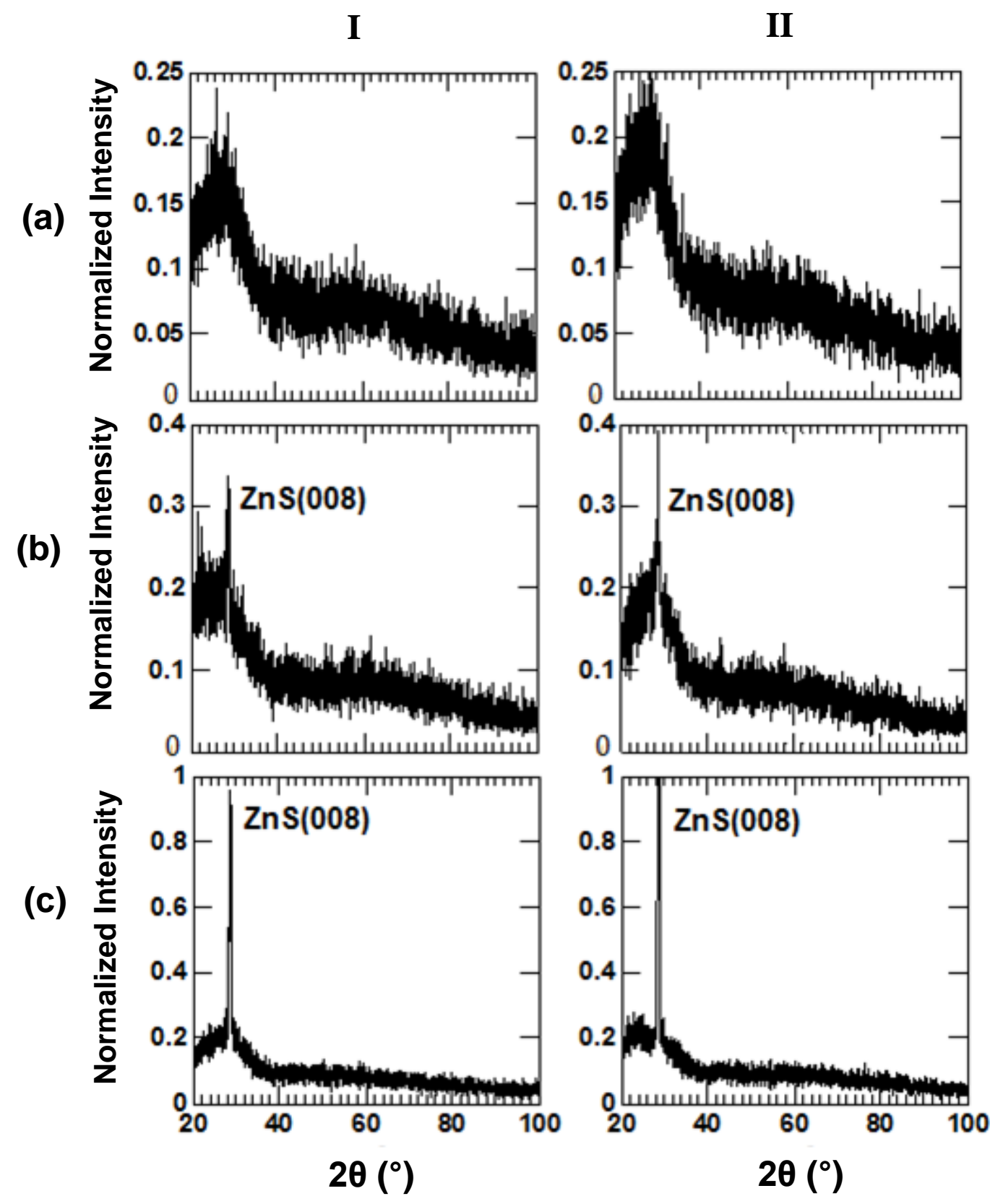

Figure 2. X-ray diffraction patterns of $\mathrm{ZnS} /$ glass (column I) and $\mathrm{ZnS} / \mathrm{ZnSgl}$ (column II) chiral sculptured thin films with different number of pitches. a) 1 pitch, b) 2 pitches, c) 3 pitches. 


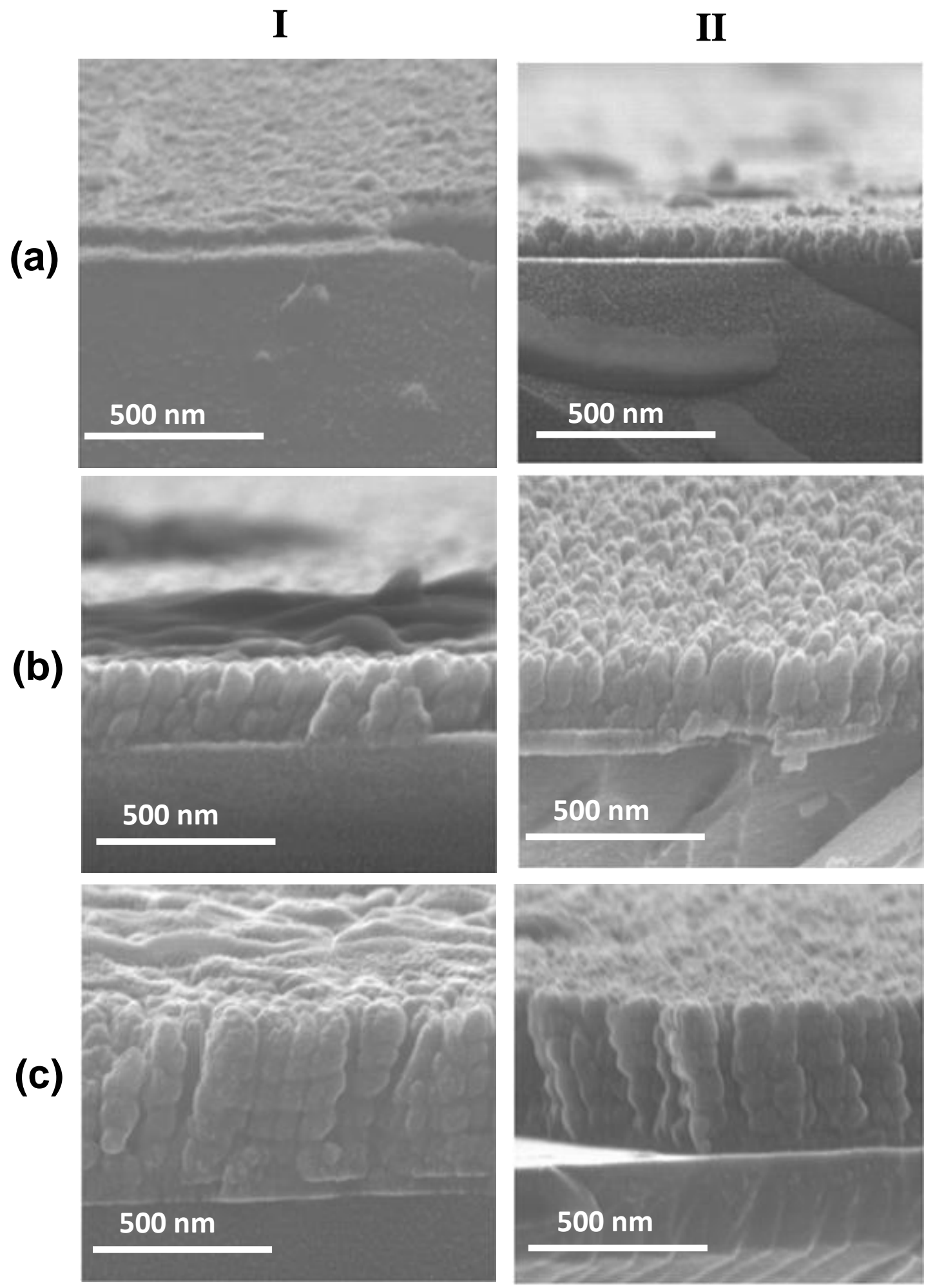

Figure 3. FESEM cross-section images of ZnS/glass (column I) and ZnS/ZnSgl (column II) chiral sculptured thin films with different number of pitches. a) 1 pitch, b) 2 pitches, c) 3 pitches. 

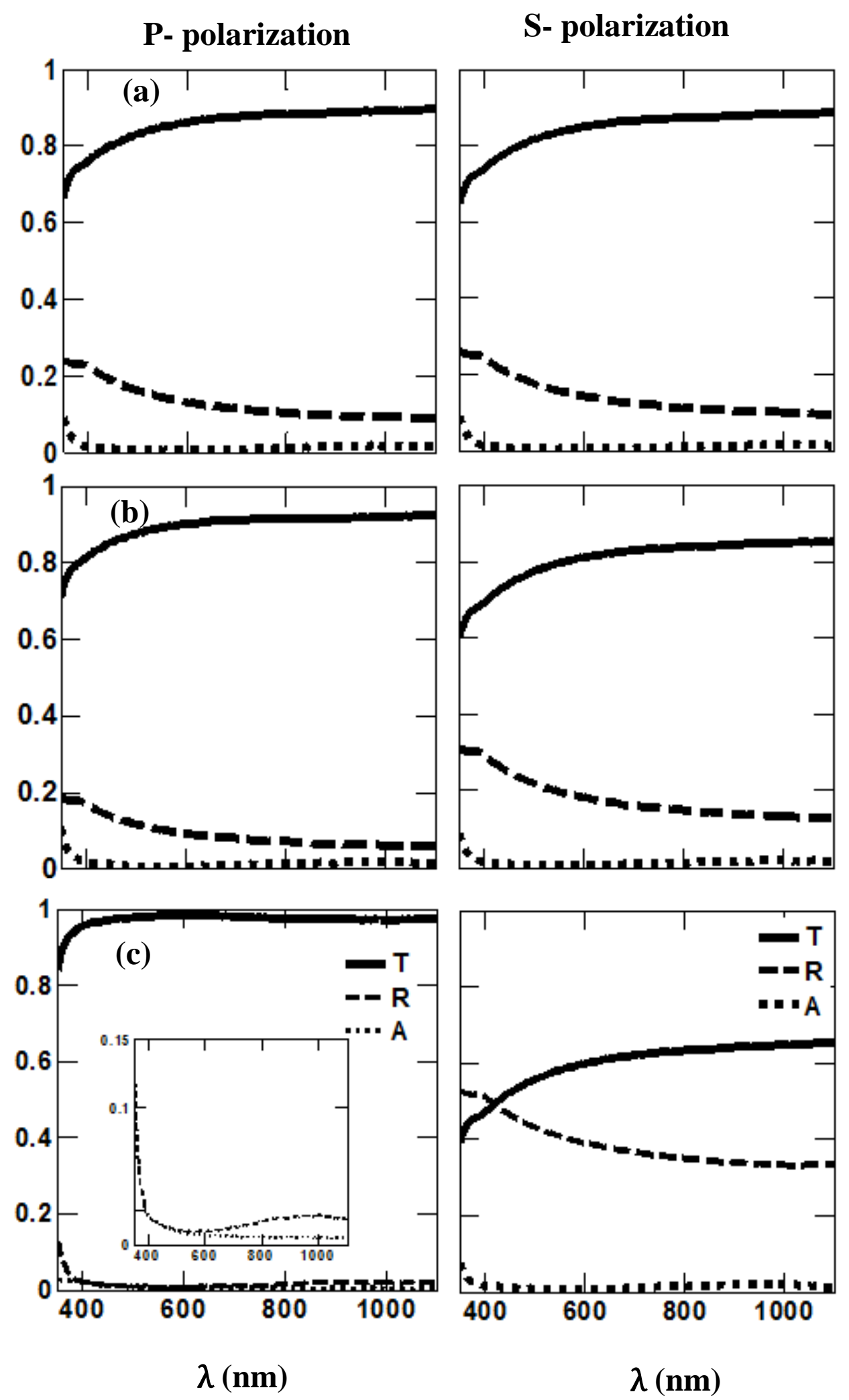

Figure 4(I) 
P-polarization
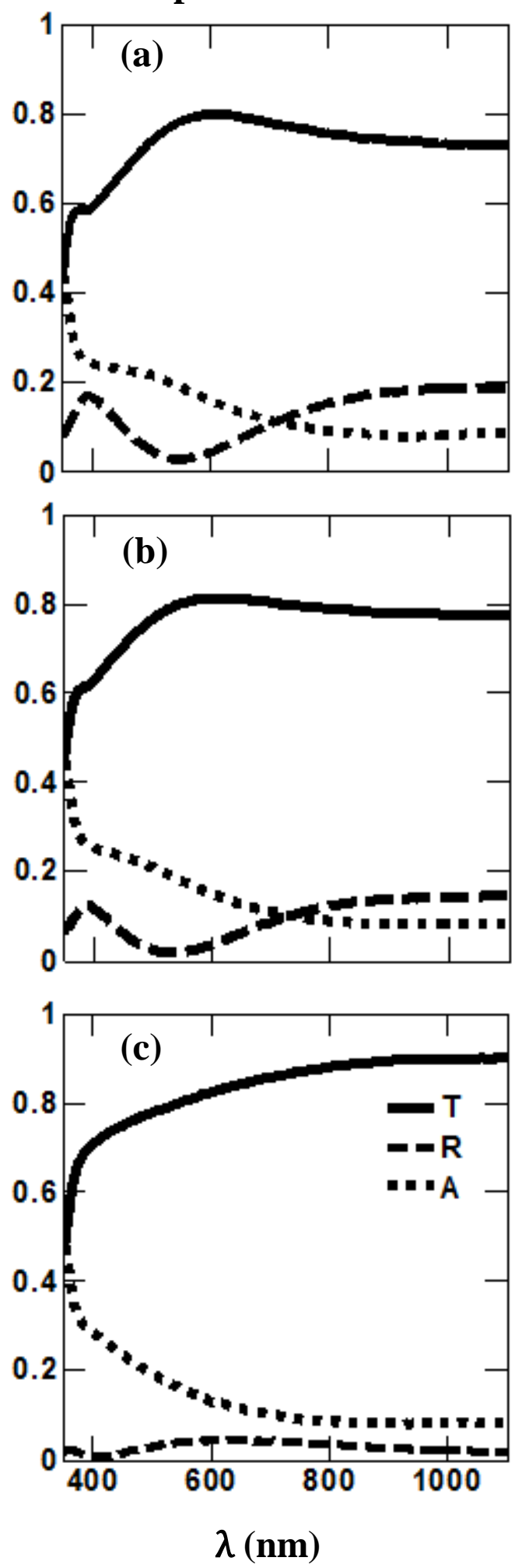

S- polarization
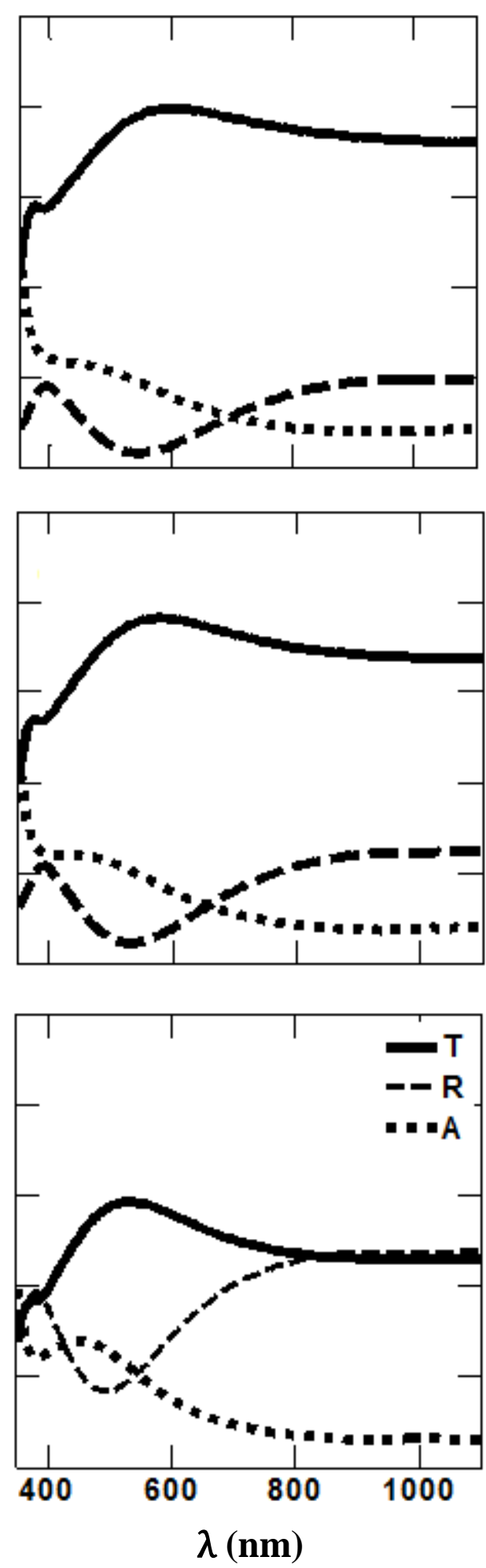

Figure 4(II) 

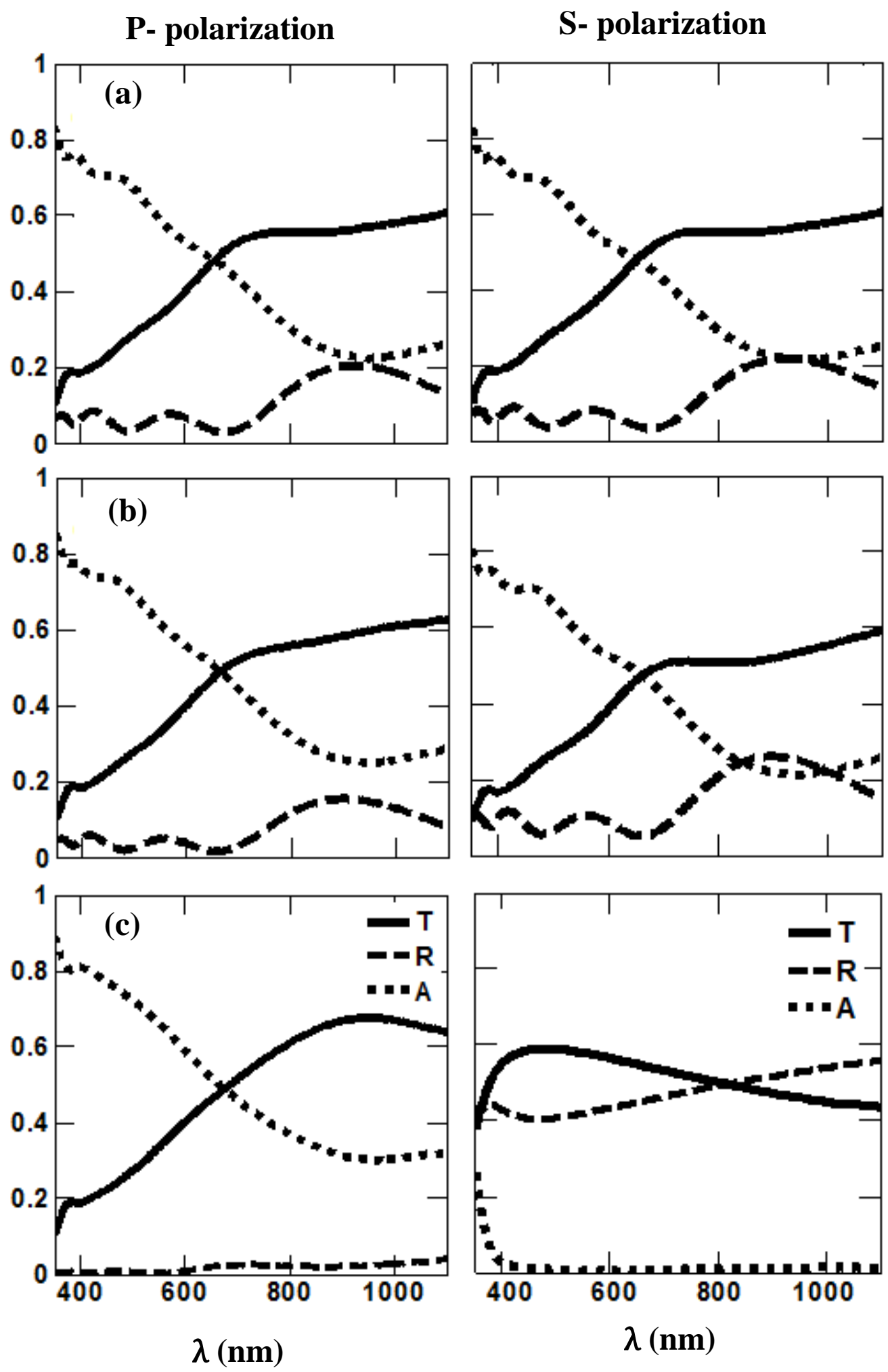

Figure 4(III)

Figure 4. Optical spectra of helical ZnS/glass sculptured thin films with different number of pitches: I) one pitch; II) three pitches; III) five pitches, obtained using different incident light angles a) $10^{\circ}$, b) $30^{\circ}$, c) $60^{\circ}$. 


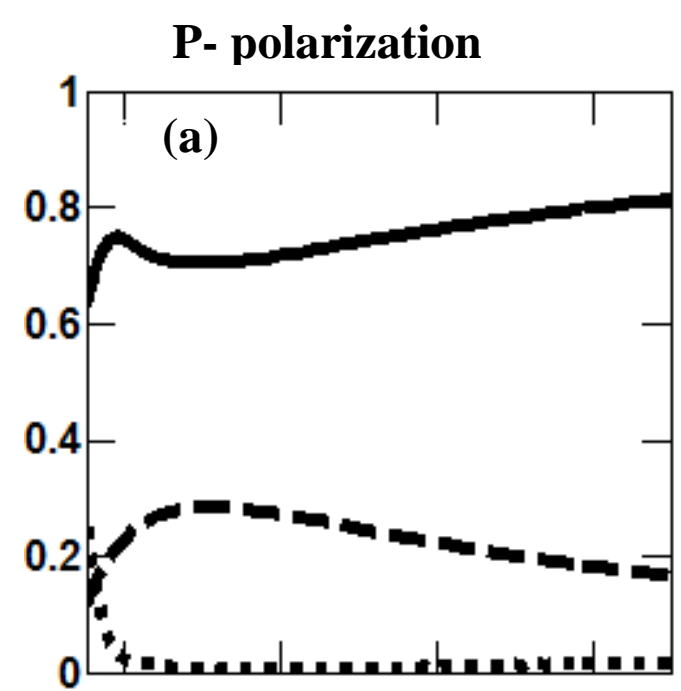

S- polarization
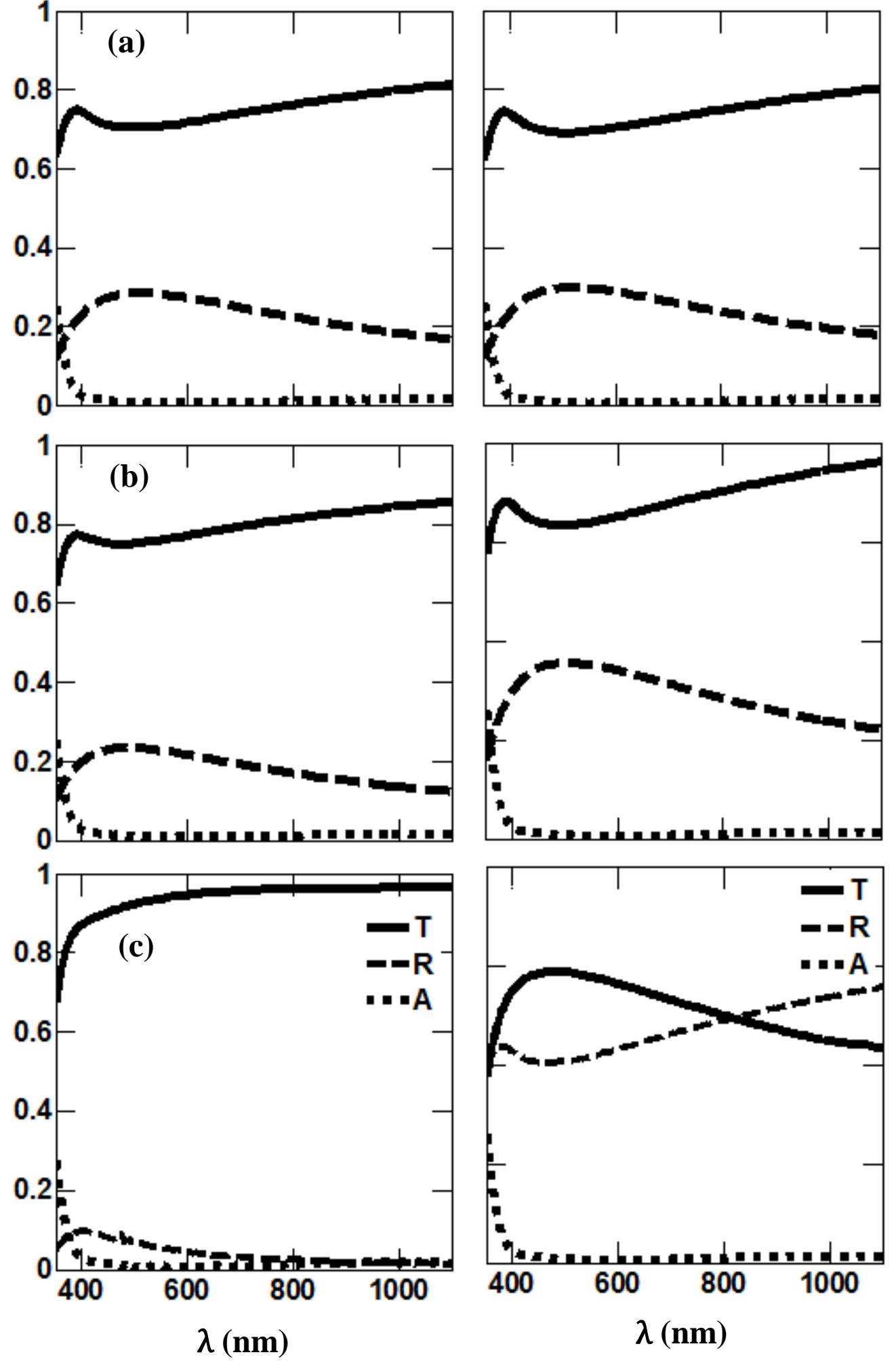

Figure 5(I) 
P- polarization
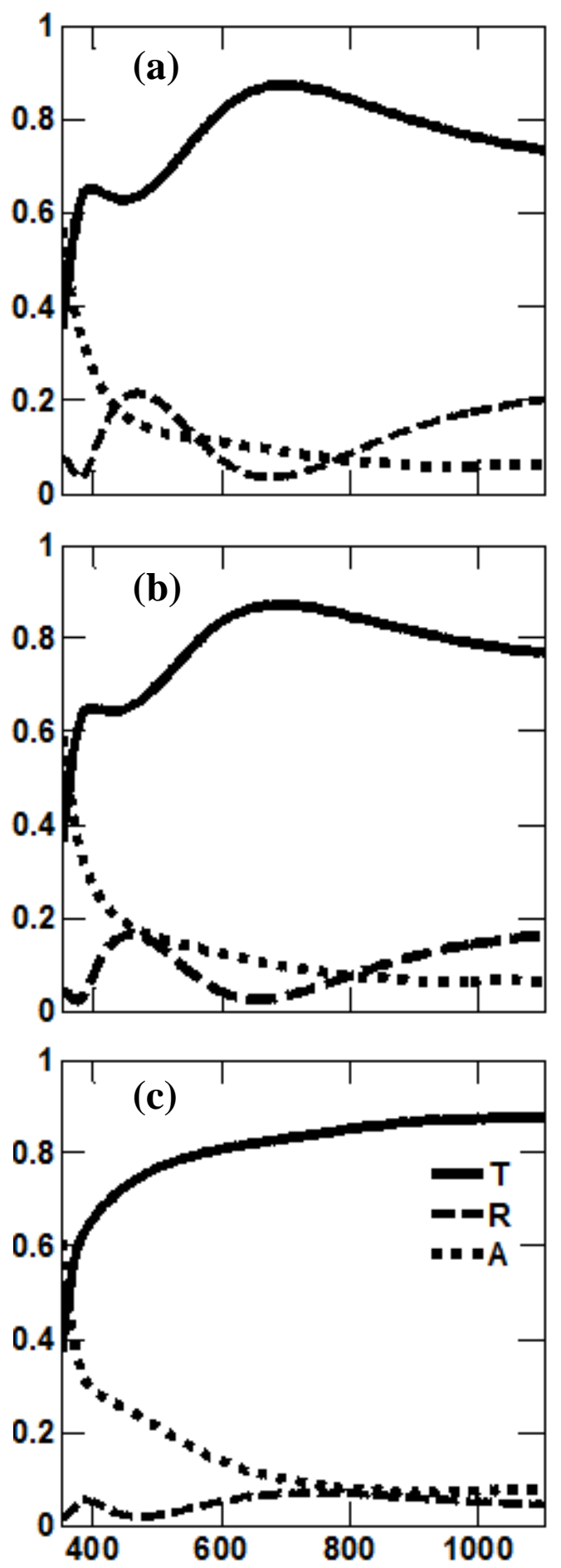

$\lambda(\mathbf{n m})$
S- polarization
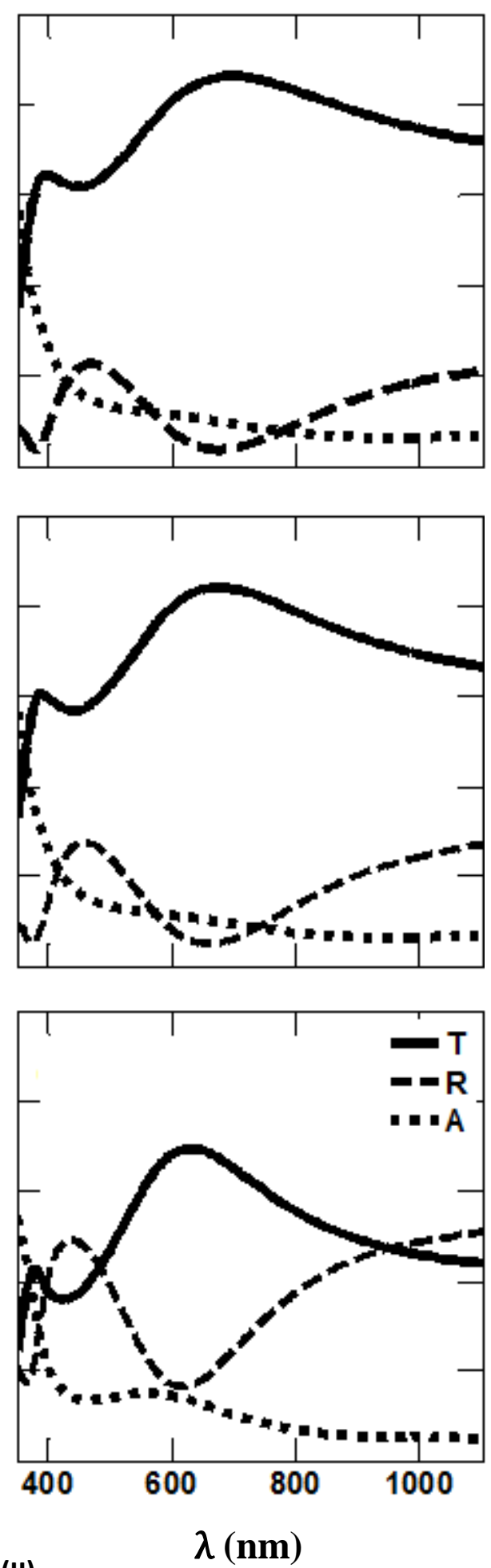

Figure 5(II) 

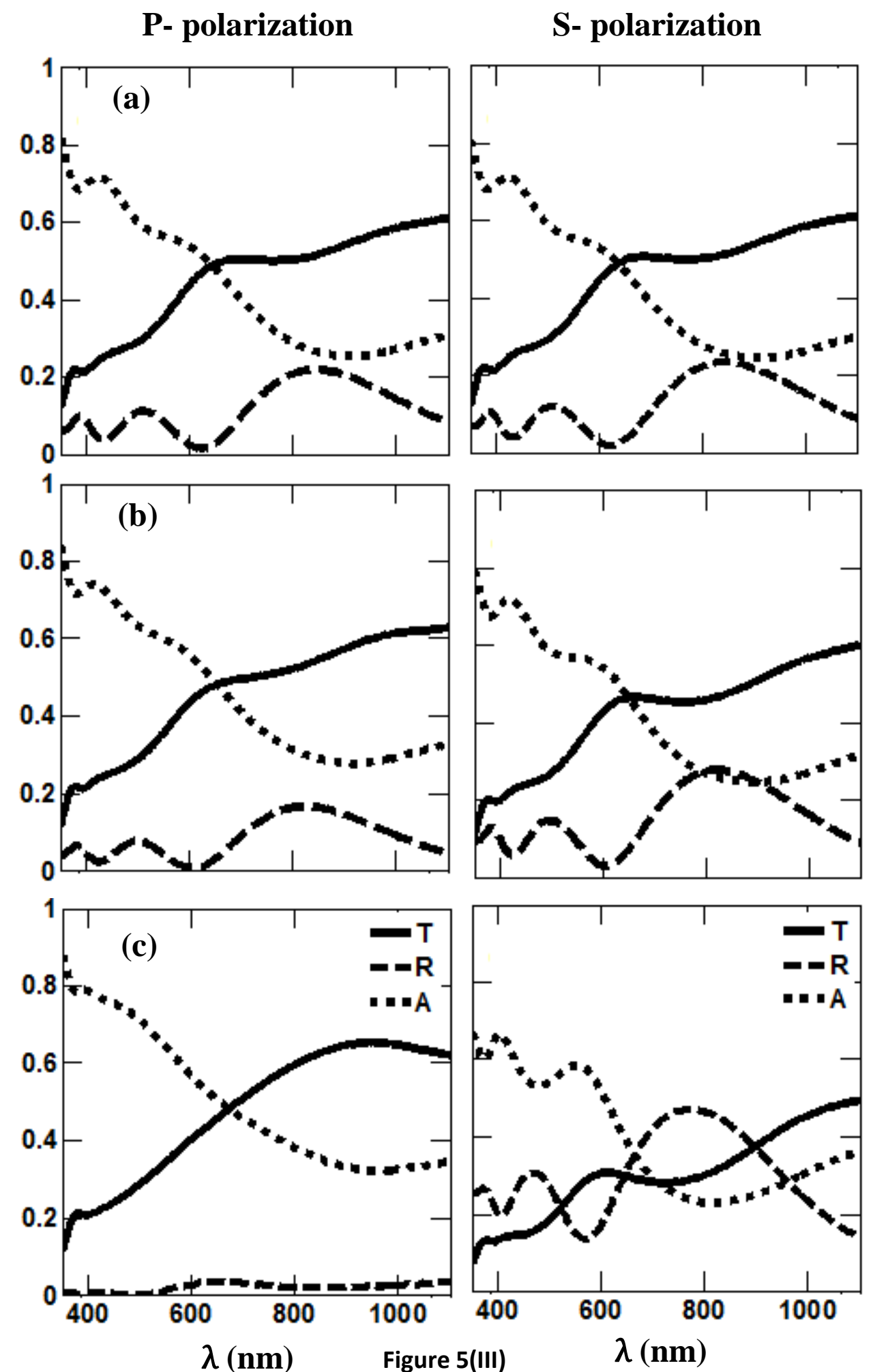

Figure 5. Optical spectra of helical $\mathrm{ZnS} / \mathrm{ZnSgl}$ sculptured thin films with different number of pitches: I) one pitch; II) three pitches; III) five pitches, obtained using different incident light angles a) $10^{\circ}$, b) $30^{\circ}$, c) $60^{\circ}$. 


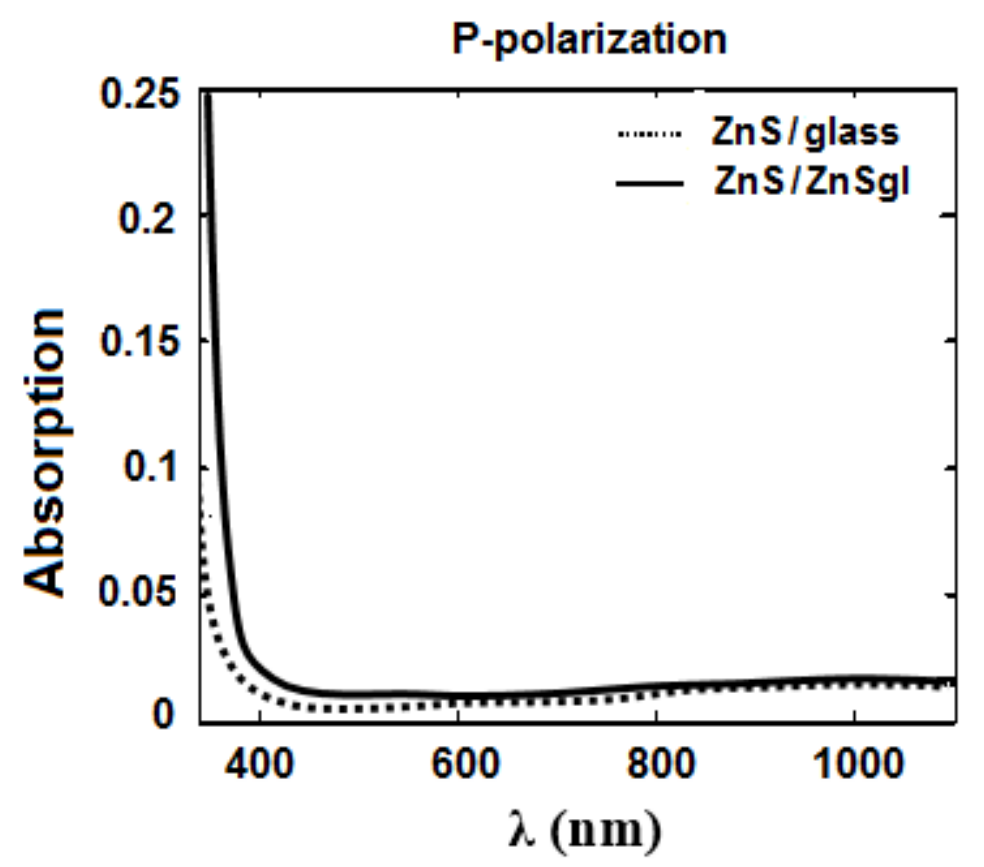

Figure 6. Shift of maximum of absorption towards shorter wavelengths for helical $\mathrm{ZnS} / \mathrm{ZnSgl}$ sculptured thin films relative to helical $\mathrm{ZnS}$ /glass sculptured thin films. 

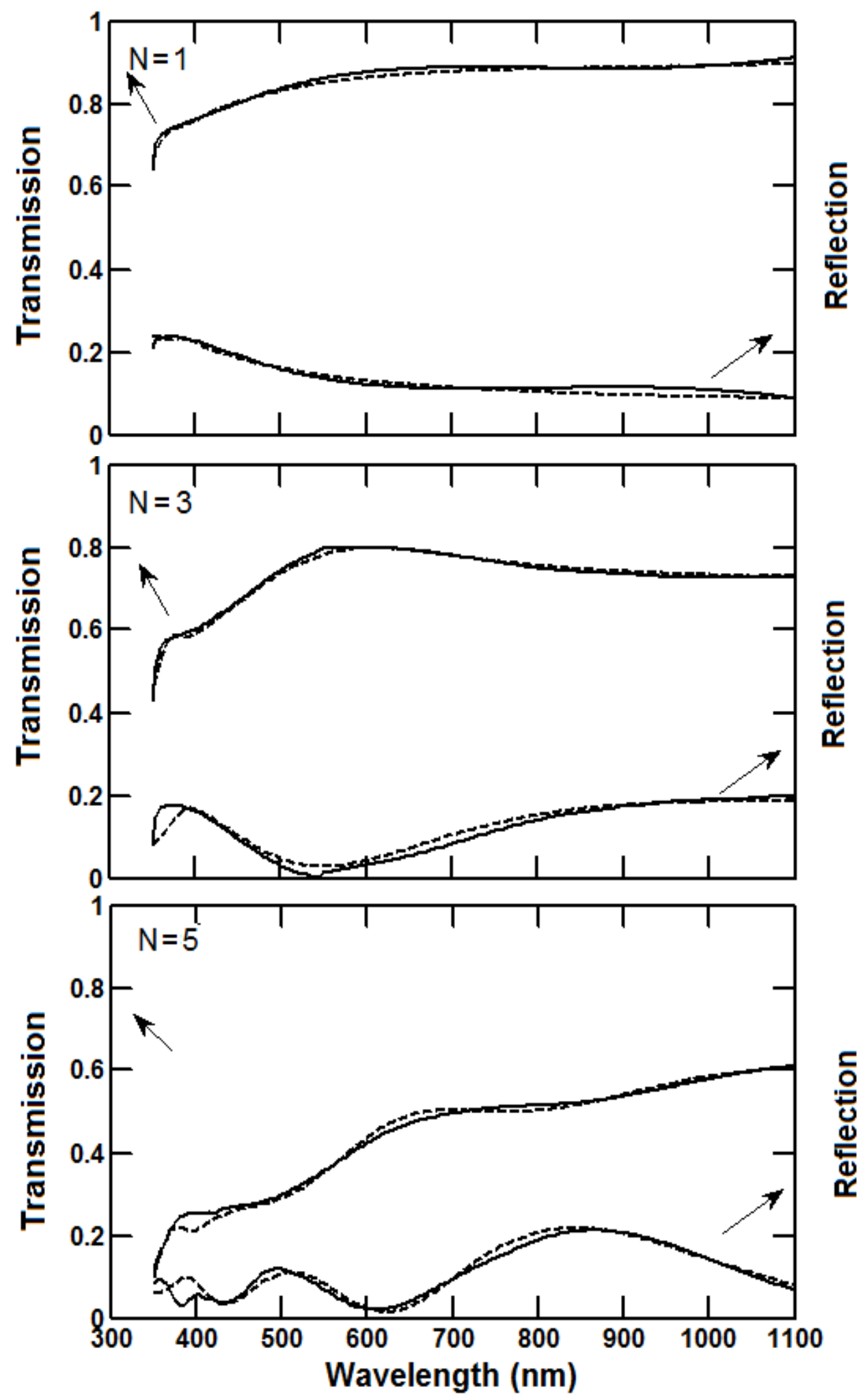

Figure 7. Optical spectra of helical ZnS/glass sculptured thin films with different number of pitches: a) one pitch; b) three pitches; c) five pitches, obtained using $10^{\circ}$ incident light angle. Solid line) results of reverse homogenization theory; Dashed line) experimental results. 

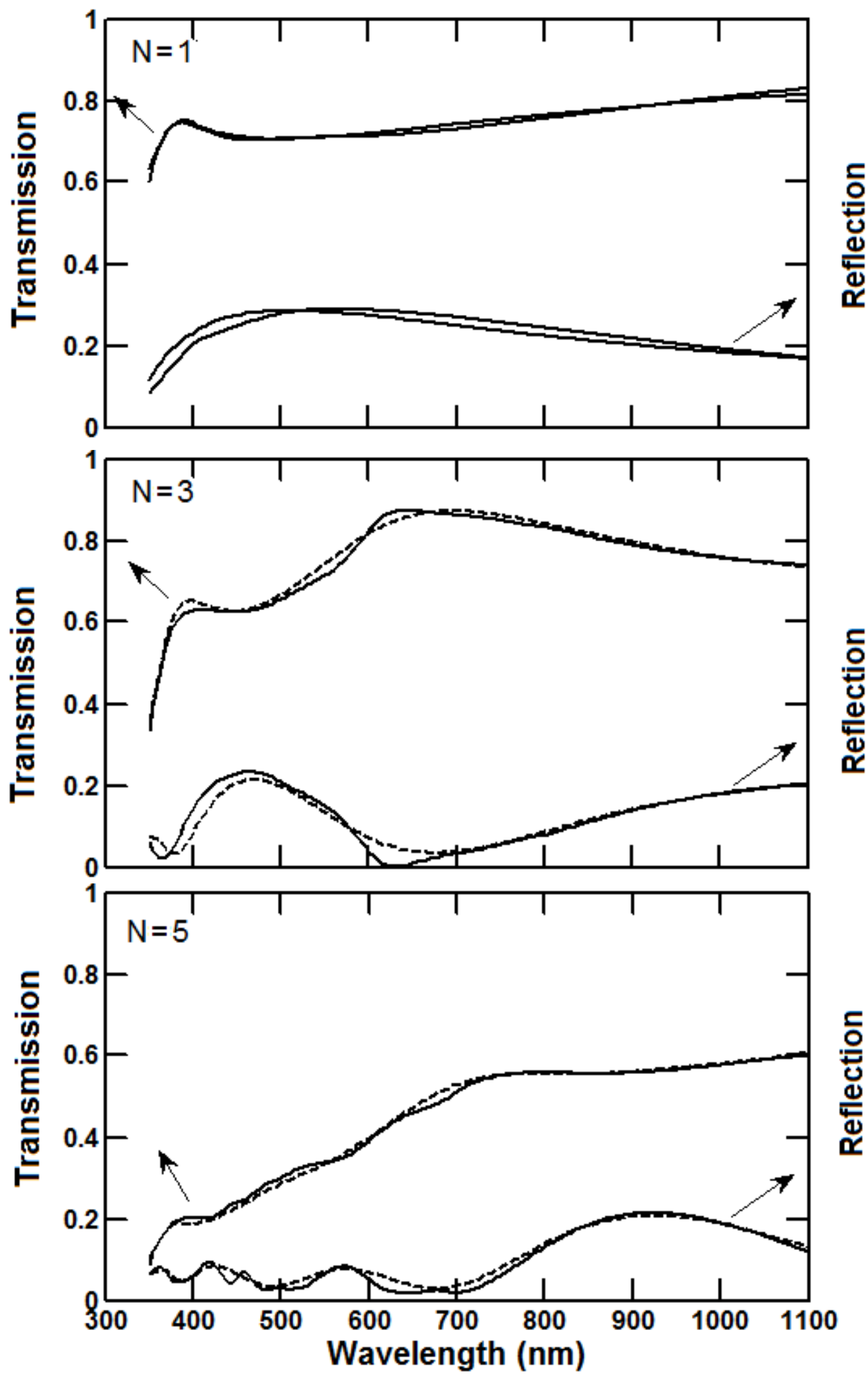

Figure 8. Optical spectra of helical $\mathrm{ZnS} / \mathrm{ZnSgl}$ sculptured thin films with different number of pitches: a) one pitch; b) three pitches; c) five pitches, obtained using $10^{\circ}$ incident light angle. Solid line) results of reverse homogenization theory; Dashed line) experimental results. 

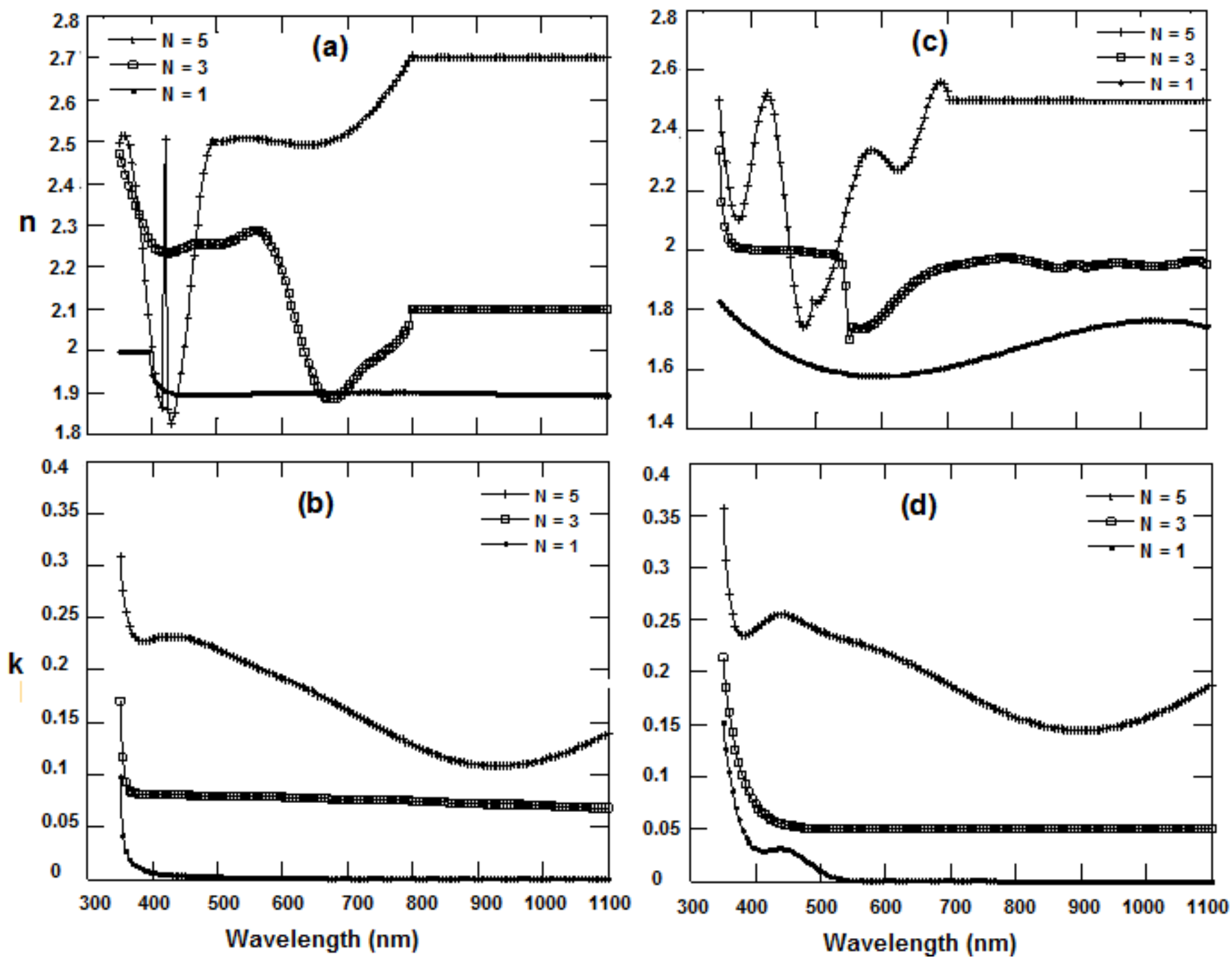

Figure 9. Real and imaginary parts of fractive index of helical $\mathrm{ZnS}$ sculptured thin films with different number of pitches $(\mathrm{N})$ on glass substrates ( $\mathrm{a}$ and $\mathrm{b}$ ) and on $\mathrm{ZnSgl} \mathrm{substrates}(\mathrm{c}$ and $\mathrm{d}$ ). 


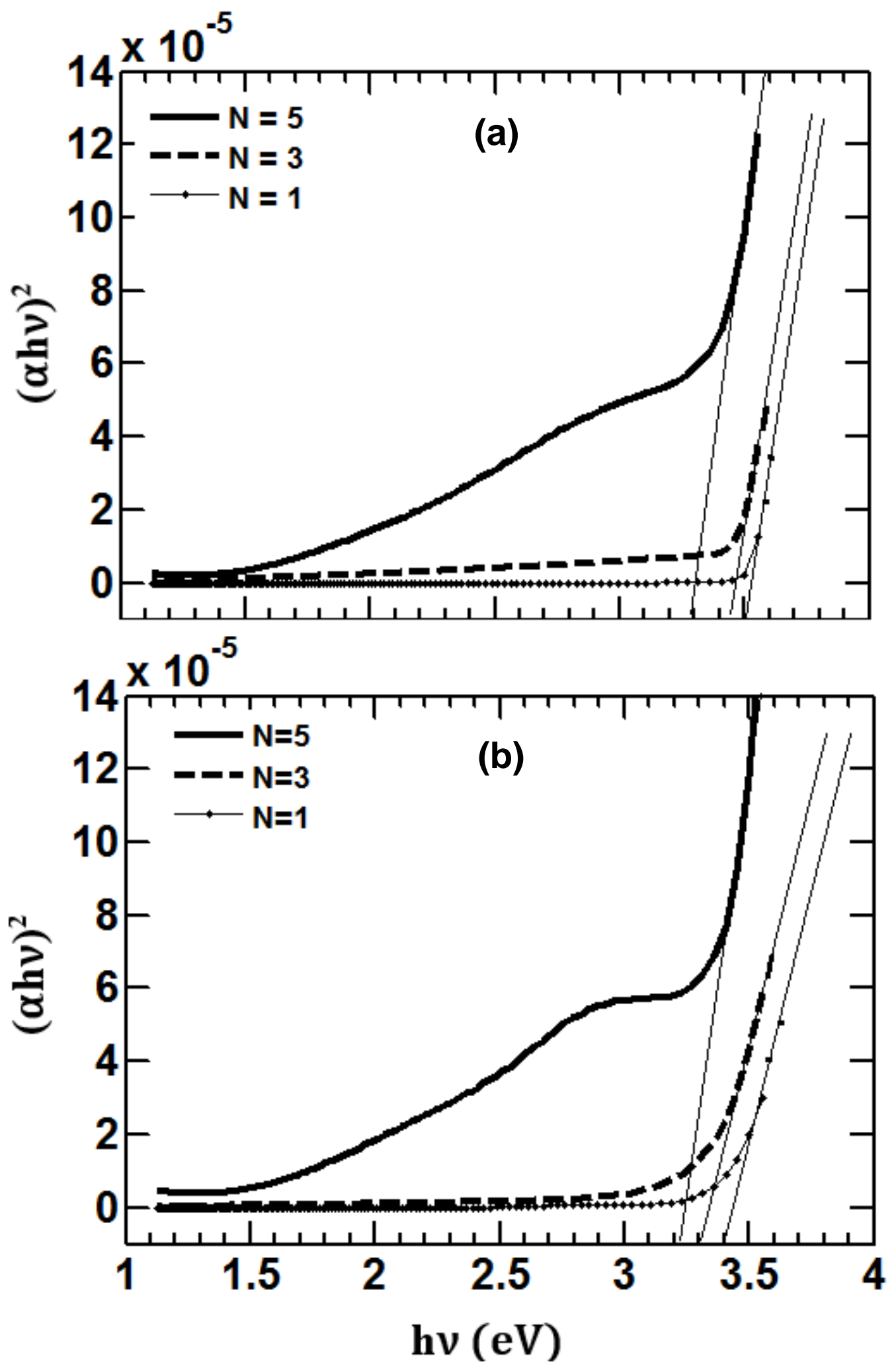

Figure 10. Band gap of helical $\mathrm{ZnS}$ sculptured thin films with different number of pitches $(\mathrm{N})$ on glass substrates (a) and on $\mathrm{ZnSgl}$ substrates (b). 